\title{
Caregiver's oral health literacy is associated with prevalence of untreated dental caries in preschool children
}

\author{
Alfabetismo em saúde bucal dos cuidadores é associado com a \\ prevalência de cárie não tratada em pré-escolares
}

Gisele Ristow Montes (https://orcid.org/0000-0003-3997-2109) ${ }^{1}$

Danielle Veiga Bonotto (https://orcid.org/0000-0003-3174-2237) ${ }^{1}$

Fernanda Morais Ferreira (https://orcid.org/0000-0001-9400-1167) ${ }^{2}$

José Vitor Nogara Borges Menezes (http://orcid.org/0000-0001-9178-0898) ${ }^{1}$

Fabian Calixto Fraiz (https://orcid.org/0000-0001-5290-7905) ${ }^{1}$
${ }^{1}$ Departamento de Estomatologia, Universidade Federal do Paraná. Av. Prefeito Lothário Meissner 632, Jardim Botânico. 80210-170. Curitiba PR Brazil fabianfraiz@gmail.com ${ }^{2}$ Departamento de Odontopediatria e Ortodontia, Universidade Federal de Minas Gerais. Belo Horizonte MG Brasil.
Abstract The aim of this study was to evaluate the relationship between oral health literacy $(\mathrm{OHL})$ among caregivers and untreated dental caries among preschoolers. A cross-sectional study was conducted involving 415 preschool children and their caregivers from Curitiba, Brazil. The children were examined for dental caries and dental plaque. The caregivers' OHL was evaluated using an instrument translated and validated for Brazilian Portuguese: the Brazilian Rapid Estimate of Adult Literacy in Dentistry-30. The prevalence of children with untreated caries was 42.9\% (95\%CI: 38.1-47.7\%). A low degree of OHL was found among $15.7 \%$ (95\%CI: 12.219.2) of caregivers. The multivariable Poisson regression analysis indicated a higher prevalence of untreated caries among children whose caregivers had a low OHL (PR = 1.35; 95\% CI: 1.01-1.79), those with visible plaque $(P R=1.28 ; 95 \% C I$ : 1.01-1.62) and those who never or only occasionally had their teeth brushed by their caregivers $(P R=1.48 ; 95 \%$ CI: 1.16-1.91) in comparison to those without these conditions. In conclusion, a higher prevalence of untreated dental caries was found among preschool children whose caregivers had a low degree of OHL.

Key words Dental caries, Health literacy, Oral health, Caregivers, Child
Resumo $O$ objetivo deste estudo foi avaliar a relação entre a alfabetização em saúde bucal (ASB) entre os cuidadores e a cárie dentária não tratada entre pré-escolares. Um estudo transversal foi realizado envolvendo 415 crianças pré-escolares e seus cuidadores de Curitiba-Brasil. As crianças foram examinadas para cárie dentária e placa dental. O ASB dos cuidadores foi avaliado usando um instrumento traduzido e validado para o idioma português do Brasil, o Brazilian Rapid Estimate of Adult Literacy in Dentistry-30. A prevalência de crianças com cárie não tratada foi de 42,9\% (IC 95\%: 38,1-47,7\%). Um baixo grau de ASB foi encontrado entre 15,7\% (IC 95\%: 12,2-19,2) de cuidadores. A análise de regressão de Poisson multivariada indicou uma maior prevalência de cárie não tratada entre crianças cujos cuidadores apresentaram baixo ASB (PR = 1,35; IC 95\%: 1,011,79), aqueles com placa visivel $(P R=1,28 ; I C$ 95\%: 1,01-1,62) e aqueles que nunca ou apenas ocasionalmente tiveram seus dentes escovados por seus cuidadores ( $P R=1,48$; IC 95\%: 1,16-1,91) em comparação com aqueles sem essas condições. Pode-se concluir que uma maior prevalência de cárie dentária não tratada foi encontrada entre os pré-escolares cujos cuidadores tinham um baixo grau de ASB.

Palavras-chave Cárie dentária, Alfabetização em saúde, Saúde bucal, Cuidadores, Criança 


\section{Introduction}

The occurrence of dental caries has been associated with socioeconomic and geographic inequalities ${ }^{1}$. Despite the considerable regional variations reported in the most recent Brazilian national oral health survey, a decline in the prevalence of dental caries has occurred, with the exception of five-year-old children, for whom the occurrence of this adverse oral health condition has remained stable ${ }^{2,3}$. This age group constitutes a challenge, as preventive actions at home as well as decisions regarding dental care and seeking dental treatment depend upon caregivers ${ }^{4}$.

Considering children's dependence on their caregivers, it is likely that, besides factors traditionally associated with dental caries, the degree of caregiver's oral health literacy also has an influence on the prevalence of this condition. Although affected by a formal education, literacy is a broader concept and encompasses the comprehension of reading, writing and interpretation skills $^{5}$. In the health field, this concept refers to "the cognitive and social skills which determine the motivation and ability of individuals to gain access to, understand and use information in ways which promote and maintain good health"6 and it is denominated health literacy. When applied to the dental field, this concept is denominated oral health literacy $(\mathrm{OHL})^{7}$.

This field of study has piqued considerable interest in recent years and OHL assessment tools have been developed employing both word recognition and comprehension. In Brazil, however, an OHL assessment tool has only recently been adapted and validated for the Brazilian Portuguese language and the cultural context of the country. The Brazilian version of the Rapid Estimate of Adult Literacy in Dentistry-30 (BREALD-30), which is based on word recognition, has proven to be simple, fast and reliable for measuring OHL among Brazilian adults ${ }^{8}$. It has demonstrated satisfactory psychometric properties (BREALD-30 scores were significantly correlated with expected variables, such as the level of general literacy, and associated with oral health outcomes, as the respondent's perception regarding his/her child's oral health), with a good internal reliability (Cronbach's alpha ranged from 0.88 to 0.89 ) and excellent reproducibility (intraclass correlation coefficient $=0.983$ and Kappa coefficient ranging from moderate to nearly perfect $)^{8}$.

The literature has demonstrated that a low OHL among adults is often associated with worse health outcomes, a less efficient use of healthcare services, history of missed dental appointments ${ }^{9}$, greater expenditures on medical and dental emergencies as well as difficulty in understanding and following the advice of healthcare professionals ${ }^{4,10-14}$. Moreover, children whose caregivers have a low degree of OHL exhibit inadequate oral health behaviors ${ }^{4,15}$ and have poorer oral health outcomes ${ }^{4,8,11,16,17}$.

The early studies cited above on OHL clearly indicate the need to broaden knowledge on the relationship between this concept and children's oral health, with the aim of enabling the implementation of educational interventions and strategies on both the community and at individual levels that are specific to each situation and, therefore, have a greater impact on health maintenance as well as on oral diseases prevention. Thus, the aim of the present investigation was to analyse the influence of caregivers' OHL on the prevalence of untreated dental caries in early childhood in a large city located in southern Brazil.

\section{Methods}

\section{Ethical aspects}

This study was conducted in compliance with the Declaration of Helsinki and received approval from the Curitiba Municipal Department of Education and Health as well as the Human Research Ethics Committee of the Federal University of Paraná, Brazil. Parents/caregivers signed a statement of informed consent allowing their children to participate in the oral examinations and provided answers to the questionnaires.

\section{Study design and sample characteristics}

A population-based, cross-sectional study was conducted involving children enrolled in the 234 educational units of the Municipal Child Education System distributed among the nine administration districts in the city of Curitiba, Brazil. In the period of this research, 15,854 preschool children were enrolled in the Municipal Child Education System. Curitiba is the capital of the state of Paraná in the southern region of the country, with an estimated population of $1,879,335$ inhabitants and a Municipal Human Development Index of $0.823^{18}$.

The calculation of the sample size was performed based on the estimated proportion for- 
mula in order to include an adequate number of individuals to compose the group to be investigated, with correction for a finite population. A 95\% confidence level $(1-\alpha)$ and 5\% acceptable error were used, considering a total population of 15,854 preschool children and the prevalence of untreated caries found in the pilot study (33.8\%). The calculated sample of 337 preschool children was multiplied by 1.2 to compensate for the cluster design effect, leading to a minimum sample of 404 preschool children, to which an additional $20 \%$ was added to compensate for possible dropouts (total: 485 preschool children and their caregivers). Two-stage (schools and children) randomized cluster sampling was employed. The sample was also stratified by regional administration district of the city (9 districts), to ensure representativeness. That is, the calculated sample size was distributed proportionally among districts, maintaining proportionality with the number of 4-5-year-old students enrolled in each district. In the first stage, schools were randomly selected by lots in each administration district. In the second stage, 4-5-year-olds were randomly selected by lots from the selected schools to reach the defined sample size for each district.

Male and female preschool children aged four and five years and their caregivers who lived in the same home participated in the study. Children who refused to allow clinical examination, had any syndrome or intellectual disability, demonstrated a debilitating condition (fever, cold, nausea, etc.) or were absent from preschool on the days of data collection were excluded from the study. The exclusion criteria for the caregivers were visual or hearing impairment (reported or perceived), not having Portuguese as their native language, having obvious signs of cognitive impairment, such as memory loss or difficulty in understanding the research objectives, and/ or drug or alcohol intoxication at the time of the interview.

\section{Data collection team, training and calibration}

The BREALD-30 was administered by a single examiner who had undergone a training exercise and was blinded to the clinical findings. After theoretical training, a set of 15 videos of adults who answered the BREALD-30 and demonstrated different degrees of OHL was used ${ }^{19}$. The gold standard in this calibration exercise was a researcher from the team that validated the questionnaire for use in Brazil. After a seven-day period, the same videos were re-evaluated. The Kappa coefficient (Kp) demonstrated that both inter-examiner and intra-examiner agreement was nearly perfect $(\mathrm{Kp}>0.90$ and $>0.91$, respectively).

The collection team for the clinical data was composed of three examiners who had undergone training and calibration exercises consisting of two steps. The theoretical step involved a discussion on the criteria employed for the diagnosis of dental caries and plaque through the analysis of photographs of these conditions. The clinical step involved the examination of 15 preschool children. After a seven-day interval, the children were examined a second time for the determination of intra-examiner agreement. A specialist in pediatric dentistry with large experience in epidemiological studies coordinated this process and was defined as the gold standard. The Kappa coefficient on a tooth-by-tooth basis was used for the analysis of agreement. With regard to visible plaque, it was only possible to determine inter-examiner agreement. Inter-examiner Kp coefficients ranged from 0.880 to 0.914 for dental plaque and 0.844 to 0.873 for dental caries. Intra-examiner Kp coefficients for dental caries ranged from 0.921 to 0.948 .

\section{Pilot study}

A pilot study was conducted involving 80 preschool children in the municipal education system in the same age group as the main study and their caregivers. All clinical examinations and the administration of the BREALD-30 were performed in compliance with pre-established codes and criteria as well as under the same conditions to be developed in the main study. The results demonstrated no need to change the proposed methods, since the number of missing data was very low and the answers presented coherence. All participants accepted the application of BREALD-30 and application time was short. The participants in the pilot study did not participate in the main study.

\section{Socioeconomic data}

A questionnaire especially elaborated for this research and previously tested in the pilot study on the socioeconomic status of the family was sent to the caregivers. This questionnaire addressed the age of the parents/caregivers, marital status, schooling, number of children, number of residents at home, monthly household income 
and access to dental services, and was answered by parents/caregivers.

\section{Evaluation of oral health literacy}

The BREALD-30 was used for the evaluation of $\mathrm{OHL}^{8}$. This assessment tool is used for a rapid estimate of OHL among adults and is administrated in a short period of time (maximum of three minutes). The BREALD-30 is composed of 30 words related to oral health arranged in an increasing order of difficulty based on length of the word, number of syllables and the difficulty in the combination of sounds. The words from BREALD-30 were read in loud voice by the caregivers in a private room at the schools where data were collected. Words pronounced correctly received a score of 1 and those pronounced incorrectly received a score of 0 . The final score was determined by the sum of the scores of the different words (total: 0 to 30), with higher scores denoting a higher degree of OHL.

\section{Clinical examination}

A clinical examination was performed on the children. The examiners used the maxillary anterior visible plaque index for the analysis of dental plaque $^{20}$. The vestibular surfaces of teeth 52,51 , 61 and 62 or their successors (teeth 12,11,21 and 22) were examined. The "d" component of the decayed, missing and filled teeth $(\mathrm{dmft})$ index was used for the determination of the prevalence of untreated dental caries, following the clinical criteria established by the World Health Organization $^{21}$. The pulp involvement, ulceration, fistula and abscess (PUFA) index was used for the examination of the clinical consequences of untreated dental caries ${ }^{22}$. Each tooth that met the criteria of the conditions of this index was cumulatively attributed one point. This evaluation was performed visually with the use of a flat mouth mirror and WHO probe for the removal of residual plaque.

\section{Statistical analysis}

The data were tabulated and organized using the SPSS Statistics ${ }^{\circledR}$ program (version 20.0; SPSS Inc., Chicago, IL, USA). The main explanatory variable (OHL measured using the BREALD-30) was dichotomised as a high or low, using as cutoff point the score of the last quintile. The clinical variables were dichotomised as follows: untreated dental caries - outcome variable (present: at least one tooth affected; absent: no teeth affect- ed); visible plaque (present: at least one maxillary anterior tooth affected; absent: no teeth affected); clinical consequences of untreated dental caries (PUFA $\geq 1$ or 0 ). The demographic and socioeconomic characteristics were dichotomised as follows: child's sex (male or female); caregiver's schooling ( $\leq$ eight years of study or more than eight years of study); caregiver's marital status (married/in a stable union or separated/widowed/single). Household income was measured based on the Brazilian minimum monthly wage (BMW), the reference of which was 296 dollars at the time of data collection. The caregivers' responses regarding oral hygiene aspects and access to dental care were dichotomised as follows: tooth brushing frequency (always or never/occasionally); difficulty regarding access to dental services (yes: did not visit a dentist due to financial difficulties; no: visited a dentist).

A descriptive analysis of the variables was performed, followed by univariate and multivariate Poisson regression analyses. Variables with a $\mathrm{p}$-value $<0.20$ in the univariate analysis were incorporated into the multivariate model and those that allowed the best fit based on the Hosmer-Lemeshow test remained in the final model. Household income and caregiver's schooling remained in the model regardless of the p-value, as these were considered possible confounding variables for the association between OHL and dental caries.

\section{Results}

A total of 415 child/caregiver pairs participated in the study, corresponding to an $85.6 \%$ response rate. The prevalence of children with untreated dental caries was $42.9 \%$ (95\% CI: 38.1 to $47.7 \%$ ). The mean BREALD-30 score was $22.8 \pm 5.1$ (median: 24; range: 0 to 30 ) and the score of 19 points was the cut-off point to the last quintile. A total of $15.7 \%$ (95\% CI: 12.2 to $19.2 \%$ ) of caregivers demonstrated a low degree of OHL and the other $84.3 \%$ (95\% CI: 80.8 to 87.8$)$ demonstrated a high degree.

Monthly household income was higher among children who were free of untreated dental caries (mean: $2.9 \pm 1.8$ BMW; median: 2.8; range: 0.4 to $11 \mathrm{BMW}$ ). Preschool children with untreated dental caries lived in families with a mean monthly income of $2.5 \pm 1.5$ BMW (median: 2.1; range: 0.5 to 8.3 ). The association of untreated dental caries and others variables was showed in the Table 1. 
OHL was significantly associated with both dental caries and its consequences (Table 2). Children whose caregivers had a low degree of OHL had a 2.06-fold greater prevalence of teeth with clinical consequences of untreated dental caries in comparison to those whose caregivers had a high degree of OHL.

The multivariate model that best explained the presence of untreated dental caries was composed of socioeconomic variables (BREALD-30 score, household income, marital status and schooling), behavioral variables (tooth brushing frequency) and clinical variables (visible plaque) (Table 3). In this model, BREALD-30, visible plaque and tooth brushing frequency were significantly associated with untreated dental caries $(\mathrm{p}<0.05)$. Higher prevalence of untreated caries was found among children whose caregivers had a low degree of OHL (PR $=1.35$; 95\% CI: 1.01 to 1.79 ), those with visible plaque ( $\mathrm{PR}=$ 1.28 ; $95 \%$ CI: 1.01 to 1.62 ) and those who never or only occasionally had their teeth brushed by their caregivers ( $\mathrm{PR}=1.48$; $95 \% \mathrm{CI}: 1.16$ to 1.91 ) in comparison to those without these conditions.

\section{Discussion}

Besides factors traditionally associated with dental caries, such as visible plaque and inadequate tooth brushing frequency ${ }^{23}$, the present findings demonstrated that a greater prevalence of untreated caries among preschool children was associated with a low degree of caregivers' OHL. Moreover, this association remained even when the multivariate model was controlled for household income as well as caregiver's marital status and schooling.

Studies often include parent's schooling as an explanatory variable for the prevalence of dental caries among children ${ }^{23,24}$. However, it is likely that the evaluation of health literacy is more sensitive to the association with health outcomes, especially in groups for which formal educational disparities are not particularly evident. Despite the increasing number of studies that have addressed this issue, few studies have evaluated such skills in terms of oral health.

Literacy and schooling are different concepts, although both are influenced by socioeconom-

Table 1. Distribution of preschool children according to caregiver's oral health literacy, schooling and marital status, visible plaque, oral hygiene and access to dental services in relation to untreated dental caries; Curitiba, Brazil, $2015(\mathrm{n}=415)$.

\begin{tabular}{|c|c|c|c|c|c|c|c|}
\hline \multirow[b]{2}{*}{ Variable } & & \multicolumn{3}{|c|}{ Untreated caries } & \multicolumn{3}{|c|}{ Univariate analysis ${ }^{\star}$} \\
\hline & & $\begin{array}{c}\text { Present } \\
\text { n(\%) }\end{array}$ & $\begin{array}{c}\text { Absent } \\
\text { n(\%) }\end{array}$ & $\begin{array}{c}\text { Total } \\
\mathbf{n}(100 \%)\end{array}$ & p-value & Crude PR & $95 \% \mathrm{CI}$ \\
\hline \multirow[t]{2}{*}{ Child's sex } & Male & $82(41.8)$ & $114(58.2)$ & 196 & 0.681 & 1 & \\
\hline & Female & $96(43.8)$ & $123(56.2)$ & 219 & & 1.05 & $0.84-1.31$ \\
\hline \multirow{2}{*}{$\begin{array}{l}\text { Caregiver's schooling } \\
\text { (years of study) }\end{array}$} & Up to 8 & $45(50.6)$ & $44(49.4)$ & 89 & 0.056 & 1 & \\
\hline & More than 8 & $124(39.7)$ & $188(60.3)$ & 312 & & 1.27 & $0.99-1.63$ \\
\hline \multirow[t]{2}{*}{$\begin{array}{l}\text { Caregiver's marital } \\
\text { status }\end{array}$} & $\begin{array}{l}\text { Married/in } \\
\text { stable union }\end{array}$ & $118(38.8)$ & $186(61.2)$ & 304 & 0.011 & 1 & \\
\hline & $\begin{array}{l}\text { Single/widowed/ } \\
\text { separated }\end{array}$ & $56(52.3)$ & $51(47.7)$ & 107 & & 1.34 & $1.07-1.69$ \\
\hline \multirow[t]{2}{*}{ BREALD-30 } & Low & $41(63.1)$ & $24(36.9)$ & 65 & $<0.001$ & 1 & \\
\hline & High & $137(39.1)$ & $213(60.9)$ & 350 & & 1.61 & $1.28-2.02$ \\
\hline \multirow[t]{2}{*}{ Visible plaque } & Absent & $94(39.0)$ & $147(61.0)$ & 241 & 0.058 & 1 & \\
\hline & Present & $84(48.3)$ & $90(51.7)$ & 174 & & 1.23 & $0.99-1.54$ \\
\hline \multirow[t]{2}{*}{ Use of toothpaste } & Never/rarely & $11(55.0)$ & $9(45.0)$ & 20 & 0.213 & 1 & \\
\hline & Always & $165(42.3)$ & $225(57.7)$ & 390 & & 1.30 & $0.86-1.97$ \\
\hline \multirow[t]{2}{*}{ Tooth brushing } & Always & $141(39.9)$ & $212(60.1)$ & 353 & $<0.001$ & 1 & \\
\hline & Never/rarely & $37(60.7)$ & $24(39.3)$ & 61 & & 1.52 & $1.20-1.93$ \\
\hline \multirow{2}{*}{$\begin{array}{l}\text { Child needed to visit } \\
\text { dentist and could not } \\
\text { afford it }\end{array}$} & Did not occur & $81(40.5)$ & $119(59.5)$ & 200 & 0.335 & 1 & \\
\hline & Occurred & $91(45.3)$ & $110(54.7)$ & 201 & & 1.12 & $0.89-1.40$ \\
\hline
\end{tabular}


Table 2. Distribution of preschoolers according to clinical variables and caregiver's oral health literacy; Curitiba, Brazil, $2015(\mathrm{n}=415)$

\begin{tabular}{llrrrrrr}
\hline \multirow{2}{*}{ Variable } & & \multicolumn{2}{c}{ BREALD-30 } & \multicolumn{3}{c}{ Univariate analysis * } \\
\cline { 3 - 8 } & & \multicolumn{1}{c}{$\begin{array}{c}\text { Low } \\
\mathbf{n}(\%)\end{array}$} & $\begin{array}{c}\text { High } \\
\mathbf{n}(\mathbf{\%})\end{array}$ & $\begin{array}{c}\text { Total } \\
\mathbf{n}(\mathbf{1 0 0 \% )}\end{array}$ & p-value & Crude PR & $\mathbf{9 5 \% ~ C I ~}$ \\
\hline Untreated caries & Absent & $24(10.1)$ & $213(89.9)$ & 237 & $<\mathbf{0 . 0 0 1}$ & 1 & \\
& Present & $41(23)$ & $137(77)$ & 178 & & 2.27 & $1.43-3.62$ \\
PUFA & Negative & $56(14.5)$ & $329(85.5)$ & 385 & $\mathbf{0 . 0 1 8}$ & 1 & \\
& Positive & $9(30)$ & $21(70)$ & 30 & & 2.06 & $1.13-3.75$ \\
Visible plaque & Absent & $35(14.5)$ & $206(85.5)$ & 241 & 0.452 & 1 & \\
& Present & $30(17.2)$ & $144(82.8)$ & 174 & & 1.19 & $0.76-1.86$ \\
\hline
\end{tabular}

* Univariate Poisson regression. ${ }^{* *}$ PUFA $=$ index used to evaluate oral conditions resulting from untreated dental caries $(\mathrm{p}-$ pulpal involvement; $\mathrm{u}$ - ulceration caused by root fragments; $\mathrm{f}$ - fistula; $\mathrm{a}$ - abscess)

$\mathrm{CI}=$ confidence interval

Crude PR = Crude prevalence ratio

Significant results at $5 \%$ level in bold

Table 3. Multivariate Poisson regression model for presence of untreated caries among preschool children; Curitiba, Brazil, 2015

\begin{tabular}{|c|c|c|c|c|}
\hline Variables & & p-value & Adjusted PR & 95\% CI \\
\hline \multirow[t]{2}{*}{ BREALD-30 } & High & \multirow{2}{*}{0.043} & 1 & \\
\hline & Low & & 1.35 & $1.01-1.79$ \\
\hline \multirow[t]{2}{*}{ Visible plaque } & Absent & \multirow{2}{*}{0.043} & 1 & \\
\hline & Present & & 1.28 & $1.01-1.62$ \\
\hline \multirow[t]{2}{*}{ Tooth brushing } & Always & \multirow{2}{*}{0.002} & 1 & \\
\hline & Never/rarely & & 1.49 & $1.16-1.91$ \\
\hline \multicolumn{2}{|c|}{ Household income (based on BMW*) } & 0.089 & 0.92 & $0.85-1.01$ \\
\hline \multirow[t]{2}{*}{ Marital status (stable union) } & Yes & \multirow{2}{*}{0.630} & 1 & \\
\hline & No & & 1.07 & $0.82-1.38$ \\
\hline \multirow[t]{2}{*}{ Caregiver's schooling } & $>8$ years & \multirow{2}{*}{0.900} & 1 & \\
\hline & $\leq 8$ years & & 1.02 & $0.76-1.36$ \\
\hline
\end{tabular}

${ }^{\star B M W}=$ Brazilian minimum wage, corresponding to US $\$ 296.00$ at time of study (2014). CI $=$ confidence interval. Adjusted PR= Adjusted prevalence ratio. Significant results at $5 \%$ level in bold.

ic and cultural contexts. Literacy, and especially health literacy, is a broader concept that the mere number of years of study and encompasses the comprehension of basic health concepts, adequate decision making and the search for healthcare services when needed ${ }^{25}$.

Adults with a low degree of OHL not only have less knowledge regarding oral health ${ }^{4,26,27}$, but also less capacity to understand health educational actions ${ }^{26}$ which makes overcoming their deficiencies more difficult. In contrast, a high degree of OHL indicates the adoption of oral health-related behaviors, such as oral self-exams, a greater frequency of oral hygiene and visiting the dentist for prevention purposes ${ }^{28}$.

Caregivers with a low degree of OHL report that their children have poorer oral health ${ }^{4,8,16}$. Moreover, such children have greater caries experience and the presence of visible plaque ${ }^{17}$ as well as the need for complex treatment due to dental caries $^{11}$. The literature indicates that a low degree of caregivers' OHL is associated with a more frequent use of night time bottle feeding ${ }^{4}$ and a failure to perform tooth brushing for their children due to frustration regarding the control of child behavior ${ }^{15}$, both of which are risk factors for den- 
tal caries. Moreover, caregivers with a low degree of OHL demonstrate difficulty understanding the importance of information on this issue and incorporating such information into their daily practices ${ }^{4}$.

An association was also found in the present study between a low degree of caregivers' OHL and greater prevalence of the clinical consequences of untreated caries, such as pulp involvement and abscess. This is the first study to investigate the association between OHL and the more extreme manifestations of dental caries. A previous study demonstrated that greater expenditures on emergency dental treatment occur among caregivers with a low degree of $\mathrm{OHL}^{10}$.

As preschool children are dependent on caregivers with regard to oral health ${ }^{29}$, it was expected that the presence of visible plaque would be influenced by OHL. However, this did not occur. It is likely that oral hygiene performed in the preschool setting, which is a frequent practice in the population studied, had an influence on this finding, even with differences in oral healthcare performed at home. Moreover, a word recognition assessment tool may not be robust enough to identify differences in oral hygiene practices as a function of the caregivers' OHL. In a study involving Asian five-year-old children, the association between a low degree of caregivers' OHL and the presence of visible plaque in children, when controlled for socioeconomic factors, only remained significant for the comprehension as- sessment tool and lost significance when the assessment tool employed was word recognition ${ }^{17}$.

One limitation of the present investigation regards the fact that the assessment tool used to measure OHL does not encompass one of the properties of functional literacy represented by the comprehension of the meaning of the words ${ }^{30}$. However, the BREALD-30 proved to allow a fast evaluation of literacy, which is an important methodological and financial gain when conducting population-based studies. Moreover, previous studies have demonstrated that $\mathrm{OHL}$ measures that involve comprehension and word recognition exhibit multicollinearit ${ }^{17}$. Another limitation of the present investigation was the inclusion of children only from the public school system. However, this aspect had the advantage of standardising some factors that could interfere with the results, such as eating practices and oral hygiene performed in the preschool setting. Lastly, the cross-sectional design does not allow the establishment of the direction of the association between OHL and dental caries. Thus, studies with a longitudinal design are needed.

In conclusion, the present findings demonstrate that caregivers' OHL was associated with the prevalence of untreated dental caries among preschool children. This indicates that clinical and health management actions should include educational strategies capable of overcoming the limitations stemming from a low degree of oral health literacy.

\section{Collaborations}

All authors have made substantive contribution to this study and/or manuscript. GR Montes, FM Ferreira and FC Fraiz were responsible for conception and design of the study. Gisele Ristow Montes and DV Bonotto participated in the data collection. The data analysis and interpretation was performed by GR Montes, DV Bonotto, JVNB Menezes, FM Ferreira and FC Fraiz. All authors contributed to the conceptual framework of article writing and interpretation of the material, as well as the final version. It has been reviewed and approved by all authors.

\section{Acknowledgments}

The authors would like to thank Francine Sumie Morikava and Giovana Solheid Gil for their assistance in data collection, and the Coordination for the Improvement of Higher Education Personnel (CAPES), which is a Foundation within the Ministry of Education in Brazil, for the financial support. 


\section{References}

1. Boing AF, Bastos JL, Peres KG, Antunes JLF, Peres MA. Social determinants of health and dental caries in Brazil: a systematic review of the literature between 1999 and 2010. Rev Bras Epidemiol 2014; 17(Supl. 2):102-115.

2. Brazil. Ministry of Health (MH). National Oral Health Survey: SB Brasil 2010. [cited 2016 Apr 20]. Available from:http://bvsms.saude.gov.br/bvs/publicacoes/ pesquisa_nacional_saude_bucal.pdf

3. Roncalli AG. National oral health survey in 2010 shows a major decrease in dental caries in Brazil. Cad Saude Publica 2011; 27(1):4-5.

4. Vann WF, Lee JY, Baker D, Divaris K. Oral health literacy among female caregivers: impact on oral health outcomes in early childhood. J Dent Res 2010; 89(12):1395-1400.

5. United Nations Educational, Scientific and Cultural Organizations (UNESCO). Literacy for Life: Education for All Global Monitoring Report 2006. 2005. [cited 2016 Apr 20]. Available from: http://www.unesco.org/ new/en/education/themes/leading-the-international-agenda/efareport/reports/2006-literacy/.

6. Nutbeam D. Health Promotion Glossary. Health Promot Int 1998; 13(4):349-364.

7. Service USPH, Services H. The Invisible Barrier: Literacy and Its Relationship with Oral Health. J Public Health Dent 2005; 65(3):174-182.

8. Junkes MC, Fraiz FC, Sardenberg F, Lee JY, Paiva SM, Ferreira FM. Validity and Reliability of the Brazilian Version of the Rapid Estimate of Adult Literacy in Dentistry--BREALD-30. PLoS One 2015; 10(7):e0131600.

9. Baskaradoss JK. The association between oral health literacy and missed dental appointments. J Am Dent Assoc 2016; 147(11):867-874.

10. Vann WF, Divaris K, Gizlice Z, Baker a D, Lee JY. Caregivers' health literacy and their young children's oral-health-related expenditures. J Dent Res 2013; 92(Supl. 1):55S-62S.

11. Miller E, Lee JY, DeWalt DA, Vann WF. Impact of caregiver literacy on children's oral health outcomes. Pediatrics 2010; 126(1):107-114.

12. Lee JY, Divaris K, Baker AD, Rozier RG, Vann WF. The relationship of oral health literacy and self-efficacy with oral health status and dental neglect. Am J Public Health 2012; 102(5):923-929.

13. Wehmeyer MMH, Corwin CL, Guthmiller JM, Lee JY. The impact of oral health literacy on periodontal health status. J Public Health Dent 2014; 74(1):80-87.

14. Hom JM, Lee JY, Divaris K, Baker AD, Vann WF. Oral health literacy and knowledge among patients who are pregnant for the first time. J Am Dent Assoc 2012; 143(9):972-980.

15. Sanzone LA, Lee JY, Divaris K, DeWalt DA, Baker AD, Vann WF. A cross sectional study examining social desirability bias in caregiver reporting of children's oral health behaviors. BMC Oral Health 2013; 13:24.

16. Divaris K, Lee JY, Baker AD, Vann WF. Caregivers' oral health literacy and their young children's oral health-related quality of life. Acta Odontol Scand 2012; 70(5):390-397.
17. Bridges SM, Parthasarathy DS, Wong HM, Yiu CKY, $\mathrm{Au}$ TK, McGrath CPJ. The relationship between caregiver functional oral health literacy and child oral health status. Patient Educ Couns 2014; 94(3):411-416.

18. Brazilian Institute of Geography and Statistics (IBGE). Cidades/Paraná/Curitiba. [cited 2016 Apr 20]. Available from: http://cidades.ibge.gov.br/xtras/ perfil.php? codmun $=410690$

19. Vilella KD, Assunção LRS, Junkes MC, Menezes JVNB, Fraiz FC, Ferreira FM. Training and calibration of interviewers for oral health literacy using the BREALD-30 in epidemiological studies. Braz Oral Res 2016; 30(1):1-7.

20. Alaluusua S, Malmivirta R. Early plaque accumulation--a sign for caries risk in young children. Community Dent Oral Epidemiol 1994; 22 (5 Pt 1):273-276.

21. World Health Organization (WHO). Oral Health Surveys - Basic Methods. Geneva: WHO; 2013.

22. Monse B, Heinrich-Weltzien R, Benzian H, Holmgren C, Van Palenstein Helderman W. PUFA - An index of clinical consequences of untreated dental caries. Community Dent Oral Epidemiol 2010; 38(1):77-82.

23. Corrêa-Faria P, Martins-Júnior PA, Vieira-Andrade RG, Marques LS, Ramos-Jorge ML. Factors associated with the development of early childhood caries among Brazilian preschoolers. Braz Oral Res 2013; 27(4):356-362.

24. Sarumathi T, Saravana Kumar B, Datta M, Hemalatha VT, Aarthi Nisha V. Prevalence, severity and associated factors of dental caries in 3-6 year old children. $J$ Clin Diagnostic Res 2013; 7(8):1789-1792.

25. Ratzan SC, Parker RM. Introduction. Natl Libr Med Curr Bibliogr Med Heal Literacy 2000; 2000-1:v-vi.

26. Tam A, Yue O, Atchison KA, Richards JK, Holtzman JS. The association of patients' oral health literacy and dental school communication tools: a pilot study. $J$ Dent Educ 2015; 79(5):530-538.

27. Parker EJ, Jamieson LM. Associations between indigenous Australian oral health literacy and self-reported oral health outcomes. BMC Oral Health 2010; 10:3.

28. Ueno M, Takeuchi S, Oshiro A, Kawaguchi Y. Relationship between oral health literacy and oral health behaviors and clinical status in Japanese adults. J Dent Sci 2013; 8(2):170-176.

29. Talekar B, Rozier G, Slade GD, Ennett ST. Parental perceptions of their preschool-aged children's oral health. JADA 2005; 136:364-372.

30. Lee JY, Rozier RG, Lee S-YD, Bender D, Ruiz RE. Development of a word recognition instrument to test health literacy in dentistry: the REALD-30--a brief communication. J Public Health Dent 2007; 67(2):9498 .

Artigo apresentado em 24/07/2017

Aprovado em 19/10/2017

Versão final apresentada em 21/10/2017 